\title{
Thermal Analysis for Peak Temperature Distribution in Reinforced Concrete Beams after Exposure to ASTM E119 Standard Fire
}

\author{
Seksith Tiantongnukul ${ }^{\mathrm{a}}$ and Akhrawat Lenwari ${ }^{\mathrm{b}}{ }^{\mathrm{b}}$ \\ Department of Civil Engineering, Faculty of Engineering, Chulalongkorn University, Phayathai Rd., \\ Pathumwan, Bangkok 10330, Thailand \\ E-mail: aseksith.ti@gmail.com, bakhrawat.1@chula.ac.th (Corresponding author)
}

\begin{abstract}
To assess the post-fire or residual strength of fire-damaged reinforced concrete (RC) members, the most detrimental or peak temperature distribution within the members should be perceived. For RC beams, the residual flexural response is strongly influenced by the peak temperature experienced by the steel reinforcements. This paper presents a simplified two-dimensional (2D) nonlinear transient thermal analysis for the peak temperature distribution in RC beams using the finite element method. In the analysis, the thermal loading for heating was the ASTM E119 standard fire. After heating, a linear decrease in temperature was assumed for cooling. Three-sided fire exposure was assumed for rectangular RC beams. The analysis was used to investigate the effects of the heating period (1-4 h), cooling period (1-4 h), concrete cover thickness $(30-50 \mathrm{~mm})$ and aggregate type (carbonate or siliceous aggregates) on the peak steel temperature and delayed time (time to attain the peak temperature after heating). The numerical results showed that the temperature inside the beam section continues to rise after heating. The increases in steel temperature after heating and delayed time are influenced by the heating period, cooling period, location of steel reinforcement, and aggregate type. Such increase is significant for the beam with a thick concrete covering subjected to a short heating period followed by a long cooling period. At the longest $(4 \mathrm{~h})$ cooling and shortest $(1 \mathrm{~h})$ heating periods, the increases in steel temperature after heating in both carbonate and siliceous concrete beams are approximately 35, 50 and $75 \%$ for concrete cover thicknesses of 30,40 , and $50 \mathrm{~mm}$, respectively. The carbonate concrete beams are more vulnerable to fire damage than siliceous ones when subjected to long heating and cooling periods.
\end{abstract}

Keywords: Finite element method, nonlinear transient thermal analysis, reinforced concrete beams, ASTM E119, fire, peak temperature distribution.

ENGINEERING JOURNAL Volume 21 Issue 4

Received 23 August 2016

Accepted 23 January 2017

Published 31 July 2017

Online at http://www.engj.org/

DOI:10.4186/ej.2017.21.4.243 


\section{Introduction}

The post-fire or residual strengths of reinforced concrete (RC) members after exposure to fire govern the decision on the appropriate repair or strengthening actions. According to a study by Kodur et al. [1], the flexural response of the fire-damaged $\mathrm{RC}$ beam depends on the internal temperatures experienced by the beam, load level during the fire event, cooling method, rate of cooling, and the strength recovery time after cooling. The residual load-carrying capacity of a fire-exposed RC beam is mainly dependent on the maximum steel reinforcement temperature attained during fire exposure. Concrete in the compression zone is less susceptible to elevated temperatures because it is usually away from the fire-exposed surface of the beam. The low thermal conductivity of concrete significantly reduces heat transfer and consequently lowers the temperature rise in the concrete core in the compression zone. In addition, the concrete strength generally has a small effect on the flexural strength of RC beams. The RC beams can retain most of the original flexural capacity after fire exposure if the maximum temperature achieved at the steel reinforcement is below $500^{\circ} \mathrm{C}$.

Previous experimental results showed that the temperature within the concrete member continues to increase after heating in the furnace [2-4]. The peak or maximum temperature at points in the beam section can occur at different time stages after heating. The temperature distribution that changes after heating reflects the progress of fire damage. To assess the post-fire response, the maximum or peak temperature distribution should be appropriately determined. Also, the residual properties of concrete and steel reinforcements to be used in a structural analysis must include both effects of heating and cooling.

Several analytical works have investigated the temperature distribution within member cross-sections and assessed the behavior of RC beams at elevated temperatures [5-10]. However, the cooling phase after heating was not considered in the analysis because the main emphasis of these studies was the fire resistance rating of $\mathrm{RC}$ beams during fire exposure. A limited number of analytical studies on the residual flexural behavior of RC beams after exposure to fire has been found [11-14]. Ožbolt et al. [14] employed a transient three-dimensional (3D) thermo-mechanical model that was implemented into a three-dimensional (3D) finite element code for predicting the temperature profiles inside the RC sections and load-deflection behaviour of the structural members subjected to thermal loads, at high temperatures or after cooling. Although the cooling phase was considered, the approach is considered to be too complicated for practicing engineers.

This paper presents a simplified two-dimensional (2D) nonlinear transient thermal analysis of RC beams to investigate the peak temperature distribution in the beam sections with an emphasis on the steel reinforcement temperature. The RC beams were exposed to the ASTM E119 standard fire (heating phase) followed by a linear decrease in temperature to room temperature (cooling phase). Three-sided fire exposure was assumed. The analysis was performed using the commercial finite element analysis software ANSYS [15]. The thermal analysis was validated with existing experimental data from the literature and then used to investigate the effects of thermal loadings, concrete properties, and concrete cover thickness on the peak temperature distribution in the beam section with the emphasis on the temperature at the critical steel reinforcement. The heating and cooling periods consisted of one, two, three, and four hours. The concrete cover thicknesses ranged from 30 to $50 \mathrm{~mm}$. Both carbonate and siliceous aggregates were considered.

\section{Thermal Properties of RC Beams}

Thermal properties of normal strength concrete are generally expressed as a function of aggregate type and temperature $[16,17]$. Aggregates can be classified into the two categories of (i) carbonate aggregates such as limestone, dolomite and basalt, whose composition is governed by calcite $\left(\mathrm{CaCO}_{3}\right)$ or dolomite $\left(\mathrm{CaMg}\left(\mathrm{CO}_{3}\right)_{2}\right)$ and (ii) siliceous aggregates such as granite, quartzite and river gravel, whose composition is governed by silica $\left(\mathrm{SiO}_{2}\right)$.

Figure 1 shows the thermal conductivity of concrete as a function of temperature [16]. The thermal conductivity decreases as the temperature increases. Typically, factors that influence the thermal conductivity include the moisture content, permeability, aggregate type, porosity and density. The thermal conductivity of aggregates primarily determines the insulating quality of concrete [18]. 


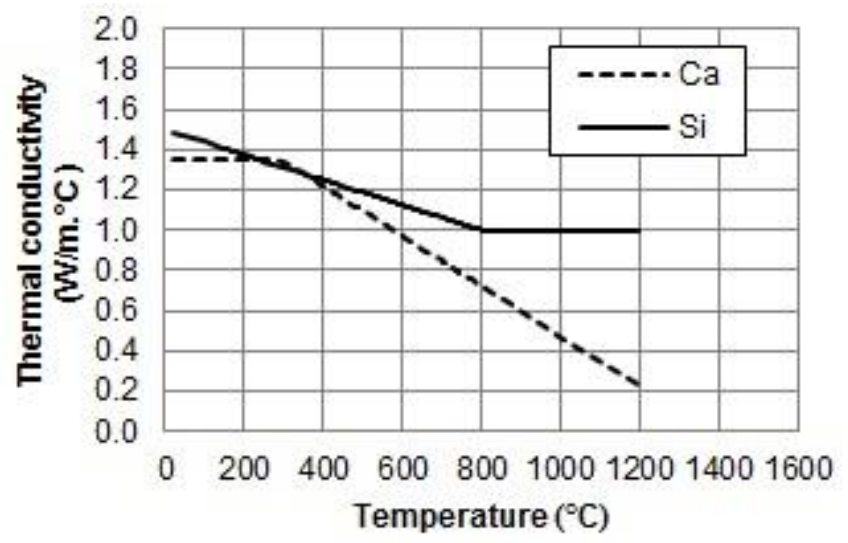

Fig. 1. Thermal conductivity of concrete [16].

Figure 2 shows the thermal or heat capacity of carbonate and siliceous concrete as a function of temperature. The thermal capacity, which is a product of the specific heat and density of concrete, increases as the temperature increases. It is dependent on the aggregate type and is highly influenced by moisture content and density of concrete [19-21]. The density of concrete decreases as the temperature increases due to the loss of moisture and chemical components. The rate of mass loss is highly dependent on the aggregate type [21]. The mass loss rates in carbonate and siliceous concrete are minimal and similar when the temperature is below approximately $600^{\circ} \mathrm{C}$. Beyond $600^{\circ} \mathrm{C}$, the mass loss rate of carbonate concrete increases and becomes significantly high, while that of siliceous concrete is still minimal. The high mass loss rate in carbonate concrete is due to the dissociation of dolomite in carbonate aggregate at temperature around $600^{\circ} \mathrm{C}[21]$.

Although the reported test data showed that both thermal conductivity and thermal capacity of concrete are also influenced by the moisture content and concrete porosity [17], such effects were not taken into consideration in this study. The thermal properties of concrete in the cooling period was assumed to be the same as those in the heating period due to the lack of thermal properties data on the cooling period [3].

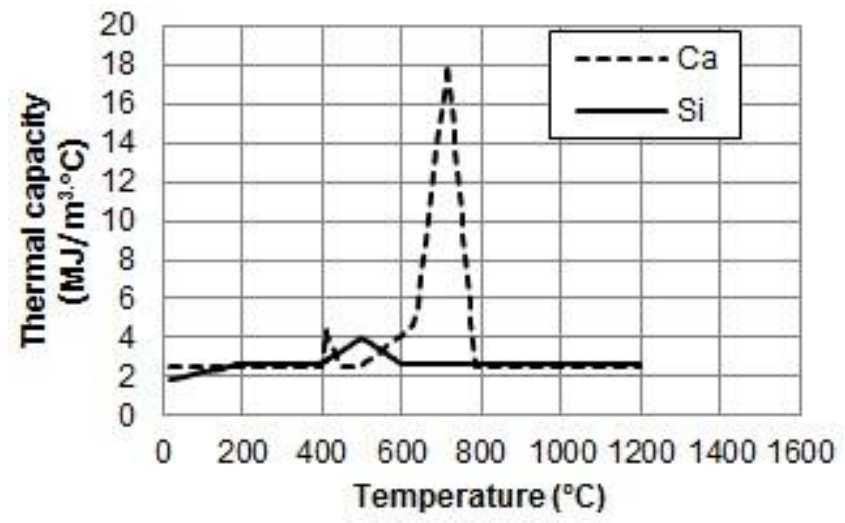

Fig. 2. Thermal (heat) capacity of concrete [16].

\section{2D Finite Element Analysis}

\subsection{Thermal Loading}

Figure 3 shows 16 idealized time-temperature curves that represent the different combinations of heating periods (hp) and cooling periods (cp) chosen in this study (1,2,3, and $4 \mathrm{~h}$ ). During heating, the rectangular RC beams were subjected to the ASTM E119 standard fire, which is given by Eq. (1) [22], 


$$
T_{f}=T_{o}+750\left(1-\exp \left(-3.79553 \sqrt{t_{h}}\right)\right)+170.41 \sqrt{t_{h}}
$$

where $T_{o}$ is the initial air temperature $\left(20^{\circ} \mathrm{C}\right), t_{h}$ is the heating period $(\mathrm{h})$, and $T_{f}$ is the fire temperature $\left({ }^{\circ} \mathrm{C}\right)$. A linear time-temperature relationship was assumed as the beams cooled to the initial temperature, as shown in Fig. 3.

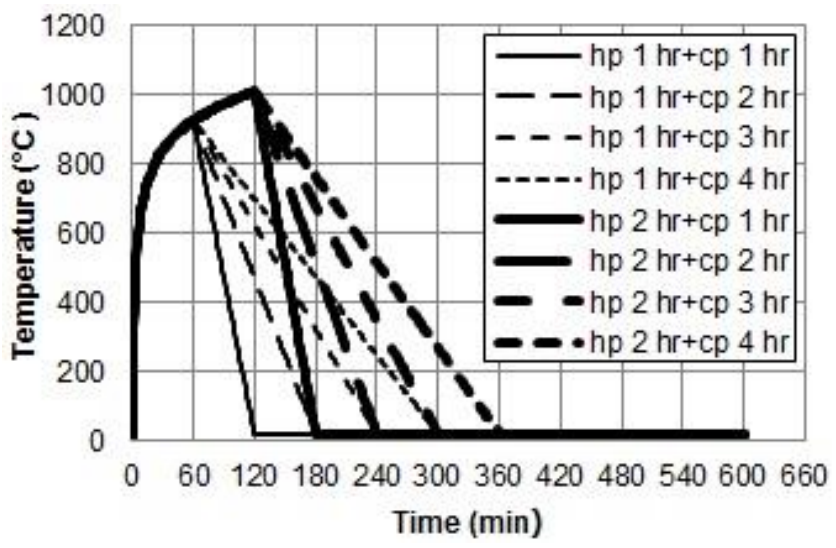

(a) 1-h and 2-h heating

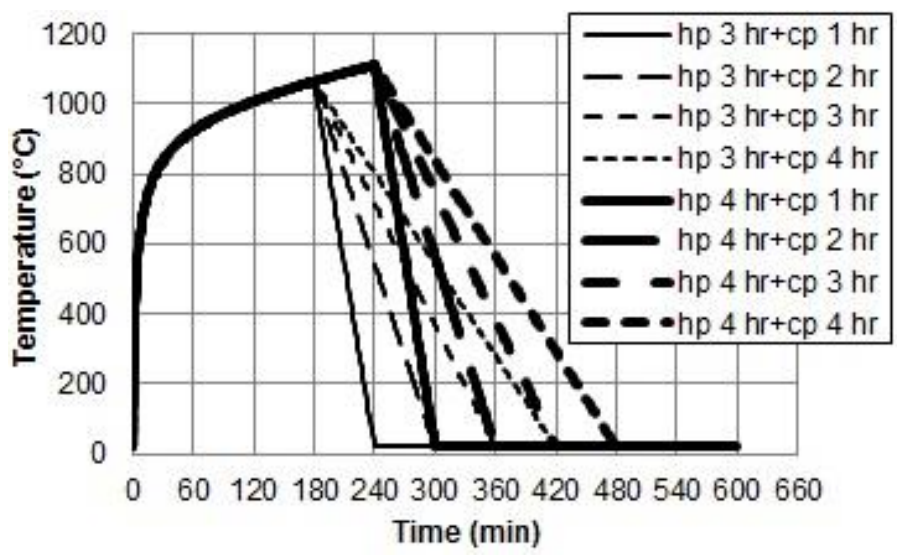

(b) 3-h and 4-h heating

Fig. 3. Idealized time-temperature curves of various heating and cooling periods in the study.

\subsection{Transient Thermal Analysis}

According to the principles of heat transfer, the heat is transferred from hot gases (thermal loading) to the surface of RC beams by radiation and convection, and then from the surface to interior by conduction. The transient heat conduction in a solid can be expressed by [23],

$$
k(T)\left[\frac{\partial^{2} T}{\partial x^{2}}+\frac{\partial^{2} T}{\partial y^{2}}\right]=\rho(T) c(T) \frac{\partial T}{\partial t}
$$

The surface boundary conditions can be expressed by

$$
-k(T)\left[\frac{\partial T}{\partial x} n_{x}+\frac{\partial T}{\partial y} n_{y}\right]=h\left[T_{f}-T_{s}\right]+\varepsilon_{r e s} \sigma\left[\left(T_{f}+273\right)^{4}-\left(T_{s}+273\right)^{4}\right]
$$


where $k(T)$ is the thermal conductivity of concrete $\left(\mathrm{W} / \mathrm{m} .{ }^{\circ} \mathrm{C}\right), \rho(T)$ is the density of concrete $\left(\mathrm{kg} / \mathrm{m}^{3}\right)$, $c(T)$ is the specific heat of concrete $\left(\mathrm{J} / \mathrm{kg} .{ }^{\circ} \mathrm{C}\right), \rho(T) c(T)$ is the thermal capacity of concrete $\left(\mathrm{MJ} / \mathrm{m}^{3} .{ }^{\circ} \mathrm{C}\right)$, $h$ is the convective heat transfer coefficient $\left(\mathrm{W} / \mathrm{m}^{2} .{ }^{\circ} \mathrm{C}\right), T$ is the concrete temperature $\left({ }^{\circ} \mathrm{C}\right), T_{f}$ is the fire temperature $\left({ }^{\circ} \mathrm{C}\right), T_{s}$ is the surface temperature $\left({ }^{\circ} \mathrm{C}\right), \varepsilon_{\text {res }}$ is the resultant emissivity of hot gases and surface of concrete (dimensionless), and $\sigma$ is the Stefan-Boltzman constant $\left(5.67 \times 10^{-8} \mathrm{~W} / \mathrm{m}^{2} . \mathrm{K}^{4}\right)$. The outward normal $\mathrm{x}$ and $\mathrm{y}$ directions of the beam surface are denoted by $n_{x}$ and $n_{y}$, respectively.

A 2D transient thermal analysis was performed using a commercial finite element software ANSYS to numerically solve Eqs. (2) to (3) for the peak temperature distribution in the fire-exposed beam sections. The finite element model employed the PLANE 55 concrete element, which has four nodes with a single degree of freedom (temperature) at each node that is applicable to a 2D steady-state or transient thermal analysis [24].

Figure 4(a) shows the beam section and boundary conditions. Dimensions of the beam section were $250 \times 450 \mathrm{~mm}$. The section was meshed into 4,500 elements having the same element size of $5 \times 5 \mathrm{~mm}$. Three-sided (two lateral sides and a bottom side) fire exposure was assumed to simulate the fire beneath a floor scenario. The steel reinforcements were not included in the model because they did not significantly influence the temperature distribution in the beam section [25]. The temperature in the steel reinforcement was assumed to be the same as the concrete temperature at the position of the steel reinforcement.

During heating, the beam section was subjected to the ASTM E119 standard fire. After the specified heating period, the temperature linearly decreased with time to $20^{\circ} \mathrm{C}$ over the specified cooling period $(1-4$ h) and then the temperature was maintained constant for $10 \mathrm{~h}(600 \mathrm{~min})$. The temperature was applied as convection on lines (section sides) with convection film coefficient values of 25 and $9 \mathrm{~W} / \mathrm{m}^{2} . \mathrm{K}$ for the exposed and unexposed surfaces, respectively $[26,27]$. The radiation effects were not considered because ANSYS can only apply the heat based on a heat source, not the surrounding gases [28]. A total of 600 load steps were chosen from time zero with a uniform temperature of $20^{\circ} \mathrm{C}$ to $10 \mathrm{~h}$.

\section{Temperature Distribution in Beam Section}

Figure 4 shows the temperature distributions in the carbonate-concrete beam section that was subjected to a 2 -h heating period followed by a 1-h cooling period at different stages during heating and cooling. The steel reinforcement located at the bottom corner, the location of which is defined by the concrete cover thickness, is the most critical among all steel reinforcements in the section. It can be seen that the temperature inside the beam section continues to increase as the thermal loading or applied temperature decreases. In case of 50-mm concrete cover thickness, the steel temperature reaches the peak temperature at $2 \mathrm{~h}$ and $42 \mathrm{~min}$.

Figure 5 shows the peak temperature distributions in the carbonate-concrete beam section subjected to a 2-h heating period followed by different cooling periods. It is evident that the damage becomes more pronounced as the cooling period increases.

Figures 6 and 7 plot the predicted temperatures at the critical steel reinforcement covered with $50 \mathrm{~mm}$ of carbonate or siliceous concrete after being subjected to a 2-h heating period and different cooling periods. For both concrete types, the corner steel reinforcement reaches the peak temperature after $2 \mathrm{~h}$ and the peak steel temperature increases as the cooling period increases. In addition, the delayed period is longer in the carbonate concrete beams than in the siliceous ones. 


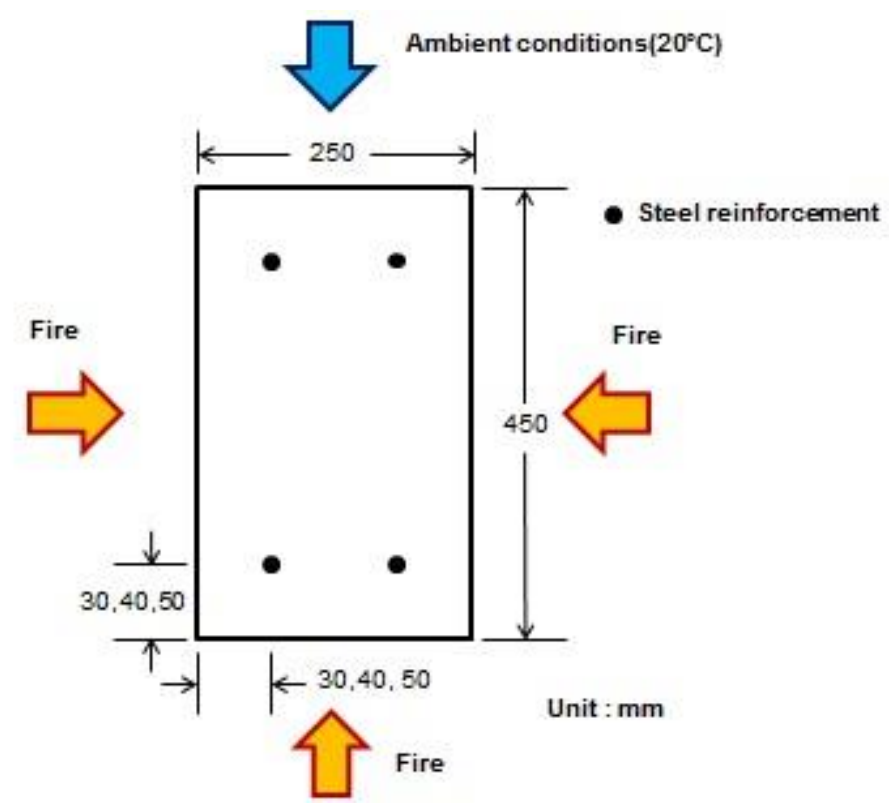

a) Cross-sectional geometry and boundary conditions in thermal analysis

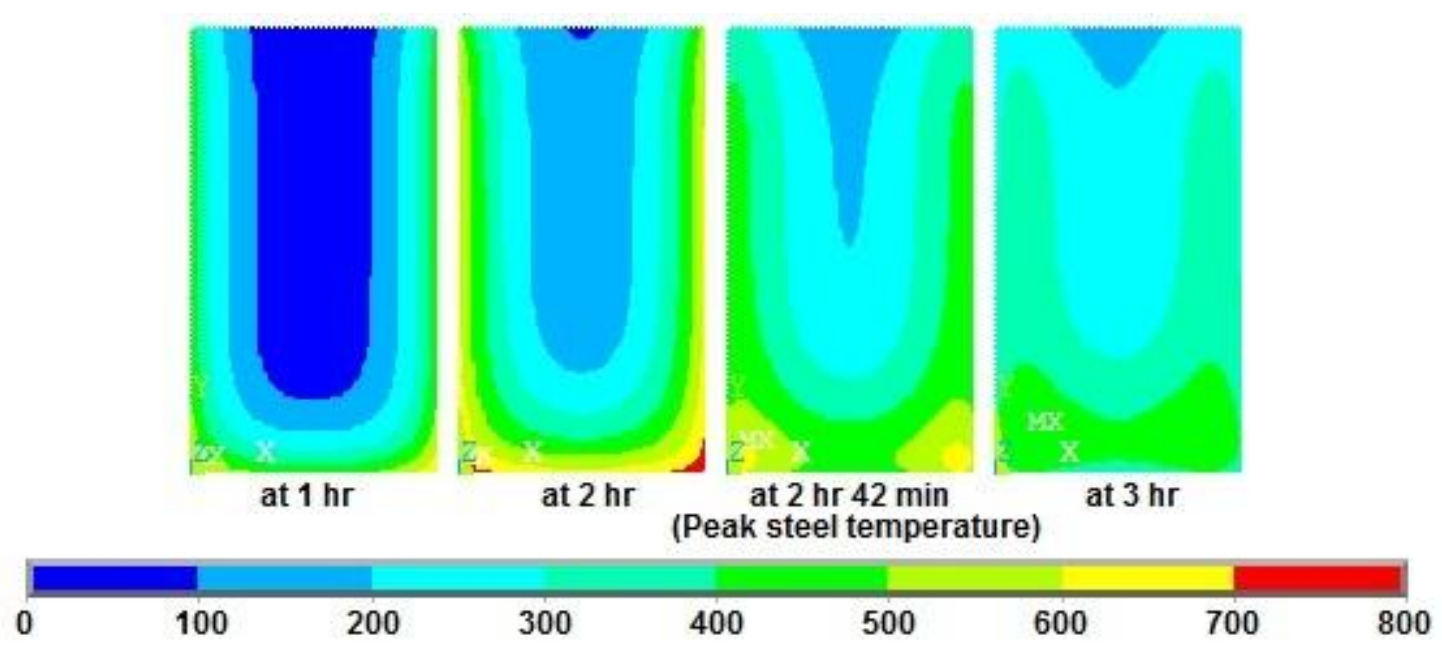

b) Temperature distributions at $1 \mathrm{~h}, 2 \mathrm{~h}, 2 \mathrm{~h} 42 \mathrm{~min}$ (at peak steel temperature for concrete cover thickness of $50 \mathrm{~mm}$ ), and $3 \mathrm{~h}$, respectively

Fig. 4. Temperature distributions in a beam section subjected to a 2 -h heating period followed by a 1 -h cooling period. 


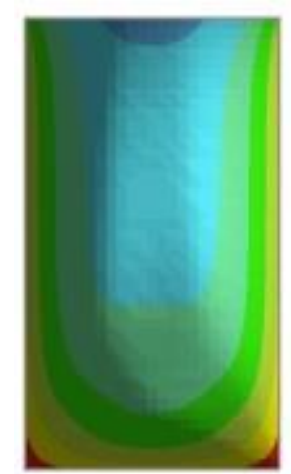

cp $1 \mathrm{hr}$

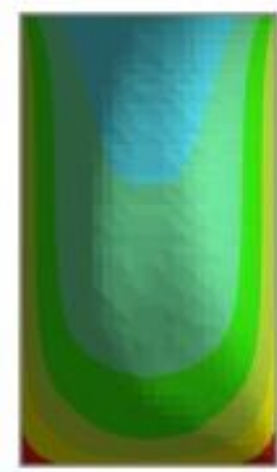

cp $2 \mathrm{hr}$

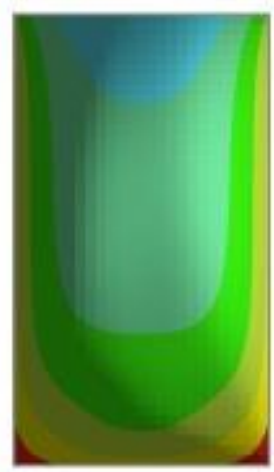

cp $3 \mathrm{hr}$

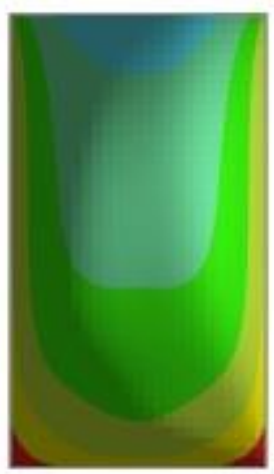

cp $4 \mathrm{hr}$

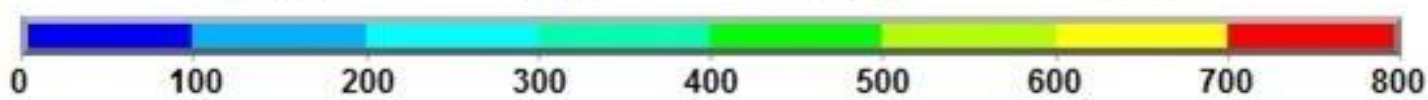

Fig. 5. Peak temperature distributions in a beam section subjected to a 2 -h heating period with a $0,1-, 2-$, 3- and 4-h cooling period (cp).

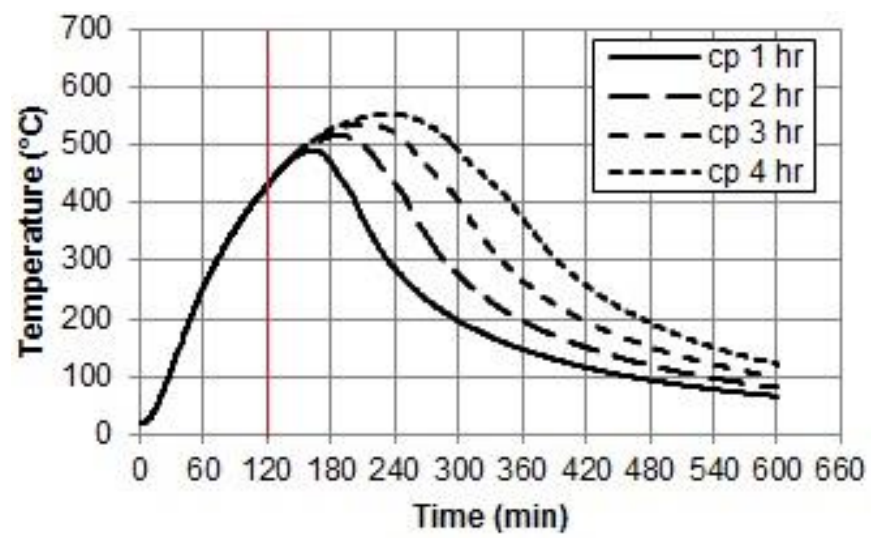

Fig. 6. Predicted steel temperature-time curves for various cooling periods (carbonate aggregates).

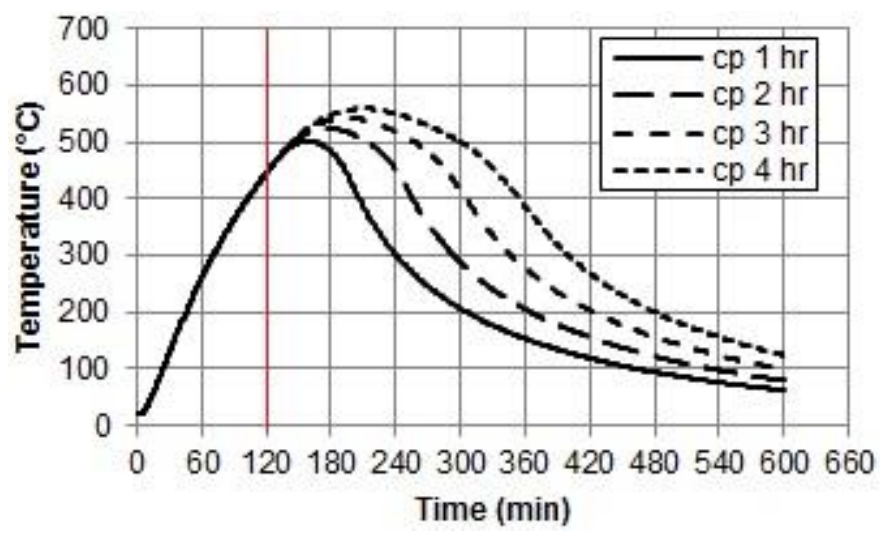

Fig. 7. Predicted steel temperature-time curves for various cooling periods (siliceous aggregates).

\section{Validation of Finite Element Analysis}

To investigate the applicability of the proposed nonlinear finite element analysis, the experimental data from a study by Dwaikat and Kodur [3] were chosen. Figure 8(a) shows the cross-sectional dimensions and thermocouple locations in beam specimen B2 [3]. The section dimensions of specimen B2 were $254 \times 406$ $\mathrm{mm}$. A normal strength concrete was used. Steel reinforcements consisted of three 19-mm diameter steel 
reinforcements in tension and two $12-\mathrm{mm}$ diameter ones in compression. The diameter and spacing of stirrups over the length of beam were 6 and $150 \mathrm{~mm}$, respectively. The finite element model used in the analysis from a convergence study is shown in Fig. 8(b). A total number of element was 336. The specimen was exposed on three sides to a design fire represented by the solid line in Fig. 9.

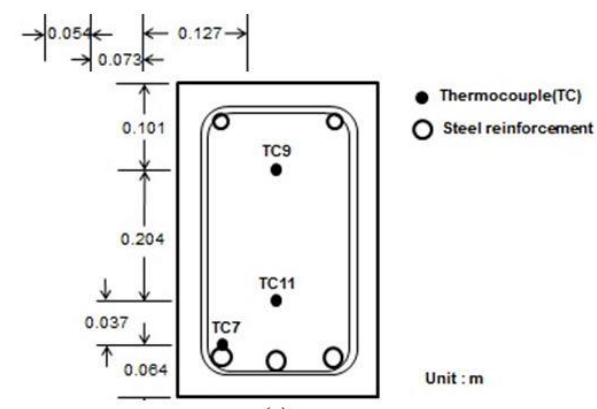

(a)

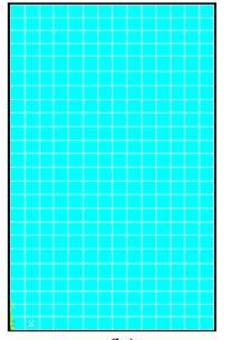

(b)

Fig. 8. Tested RC beam specimen B2 [3] (a) dimensions and thermocouple locations (b) finite element model.

Figure 9 shows a comparison between the predicted and measured temperatures at three thermocouple locations including the corner steel reinforcement (TC7) and concrete (TC9 and TC11). Good agreement was observed. It should be noted that the fire curve used in the analysis did not perfectly simulate the experimental one. Noticeably, the peak temperatures at all locations occur at the time well beyond one hour, the time at which the furnace temperature started to decrease. More detailed validation results with previous studies are provided in Tiantongnukul [29].

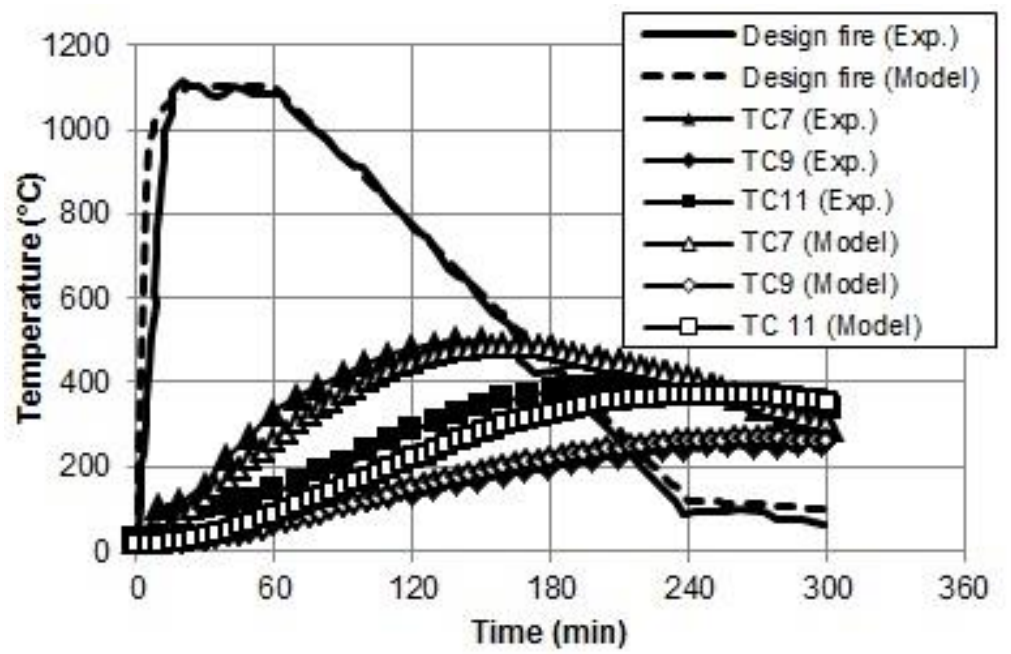

Fig. 9. Comparison between the predicted and measured temperatures in specimen B2 [3].

\section{Parametric Study}

The effects of heating period, cooling period, location of the steel reinforcement, and aggregate type were numerically investigated by the proposed analysis. Hereafter, the $T_{\text {heat }}$ and $T_{\text {peak }}$ represent the temperatures of the steel reinforcement at the end of heating and the maximum (or peak) temperature, respectively. This $\mathrm{T}_{\text {peak }} / \mathrm{T}_{\text {heat }}$ ratio indicates the increase in temperature (damage) after heating. The theat and $t_{\text {peak }}$ represent the heating period and the time to achieve the peak steel temperature, respectively. This $t_{\text {peak }} / t_{\text {heat }}$ ratio indicates the delayed time. 


\subsection{Effects of Heating and Cooling Periods}

Figures 10 to 12 show the effects of heating and cooling periods on $\mathrm{T}_{\text {peak }} / \mathrm{T}_{\text {heat }}$ and $\mathrm{t}_{\text {peak }} / \mathrm{t}_{\text {heat }}$ ratios at the critical steel reinforcement for concrete cover thicknesses of 30, 40, and $50 \mathrm{~mm}$, respectively. All figures show that $\mathrm{T}_{\text {peak }} / \mathrm{T}_{\text {heat }}$ ratio increases as the cooling period increases. For each concrete cover thickness, the relationship between $T_{\text {peak }} / T_{\text {heat }}$ ratio and cooling period is almost linear at a specific heating period. Therefore, a gradual (long) cooling period causes more damage than a sudden cooling after heating. However, the effect of cooling period becomes less pronounced at a long heating period. For a specific cooling period, the $\mathrm{T}_{\text {peak }} / \mathrm{T}_{\text {heat }}$ ratio decreases with increasing heating period as a result of the high steel temperature during heating. For the heating period beyond $2 \mathrm{~h}$, the increases in steel temperature are less than 15,20 , and $30 \%$ for concrete cover thicknesses of 30,40 , and $50 \mathrm{~mm}$, respectively. Similar trends are observed for the $t_{\text {peak }} / t_{\text {heat }}$ ratio that indicates the delayed time.

The effects of aggregate types on the temperature increase and delayed time are minimal at a short heating period $(\leq 1 \mathrm{~h})$, but become significant at long heating periods. The longer heating and cooling periods causes more damage to the carbonate concrete beams than the siliceous ones.

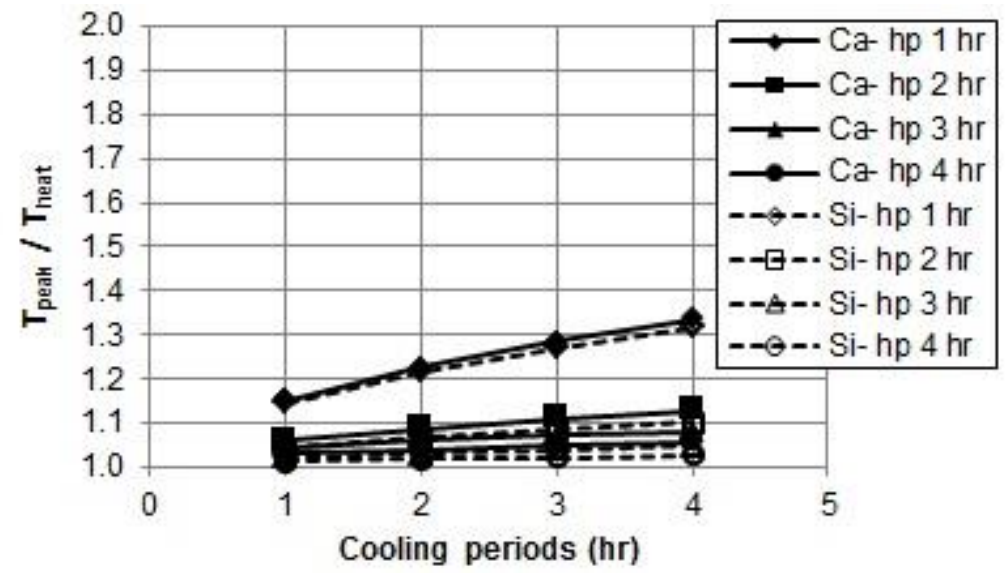

(a)

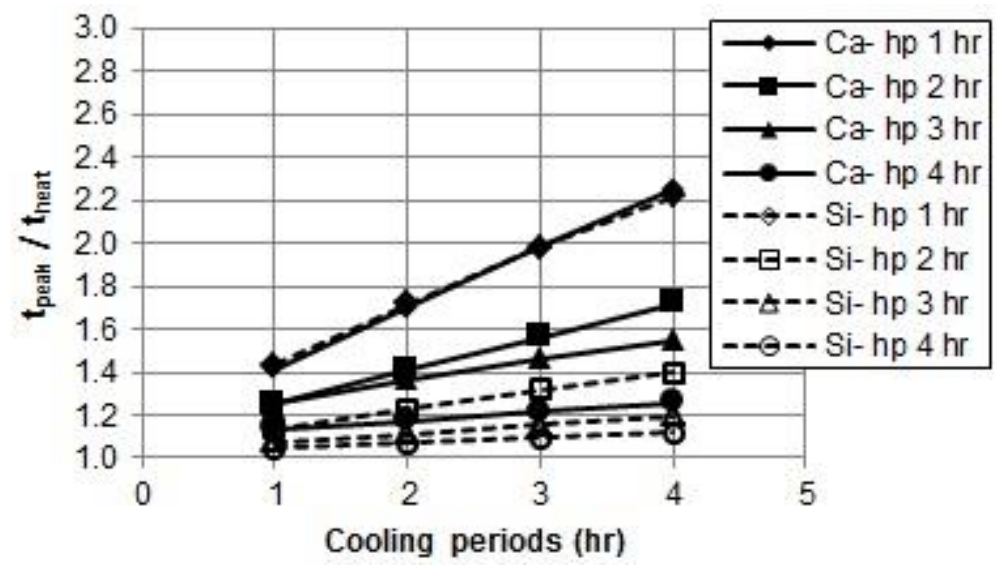

(b)

Fig. 10. Effects of heating and cooling periods on (a) $\mathrm{T}_{\text {peak }} / \mathrm{T}_{\text {heat }}$ ratio and (b) $t_{\text {peak }} / t_{\text {heat }}$ ratio at the steel reinforcement (concrete cover thickness of $30 \mathrm{~mm}$ ). 


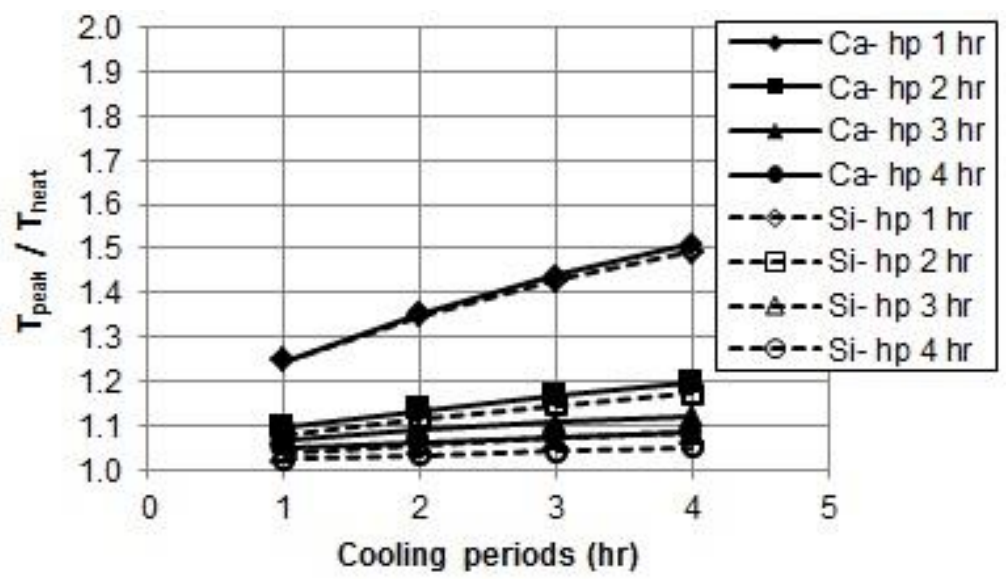

(a)

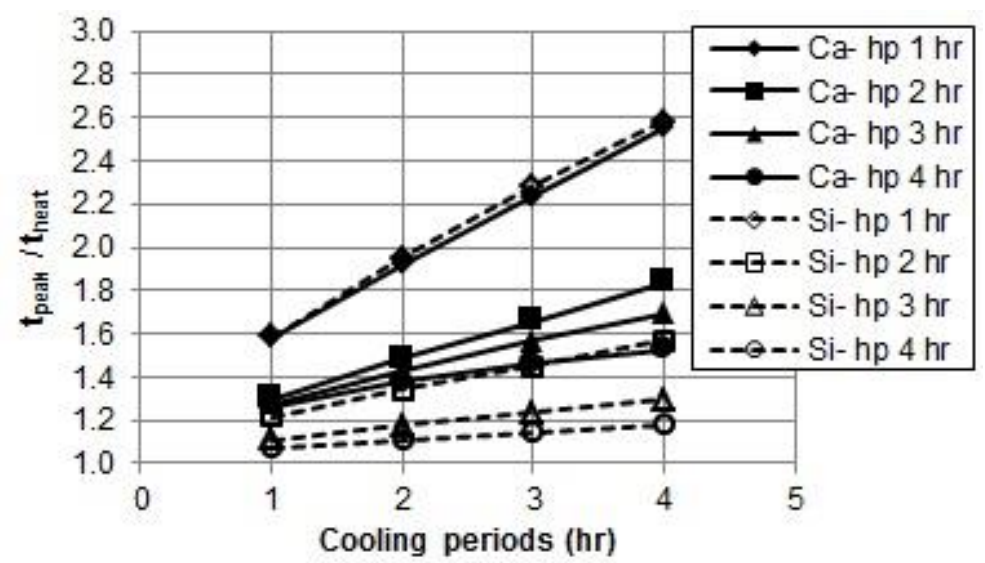

(b)

Fig. 11. Effects of heating and cooling periods on (a) $T_{\text {peak }} / T_{\text {heat }}$ ratio and (b) $t_{\text {peak }} / t_{\text {heat }}$ ratio at the steel reinforcement (concrete cover thickness of $40 \mathrm{~mm}$ ).

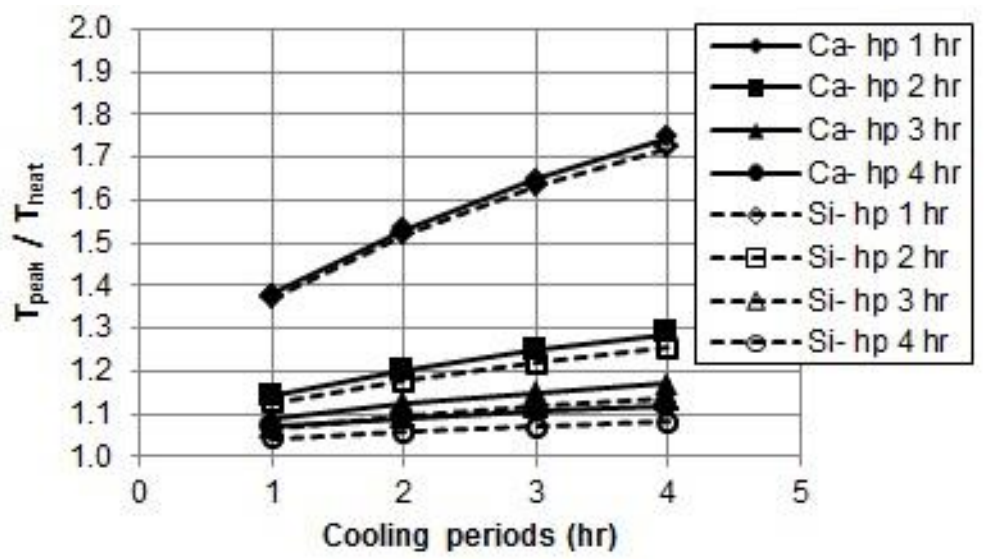

(a) 


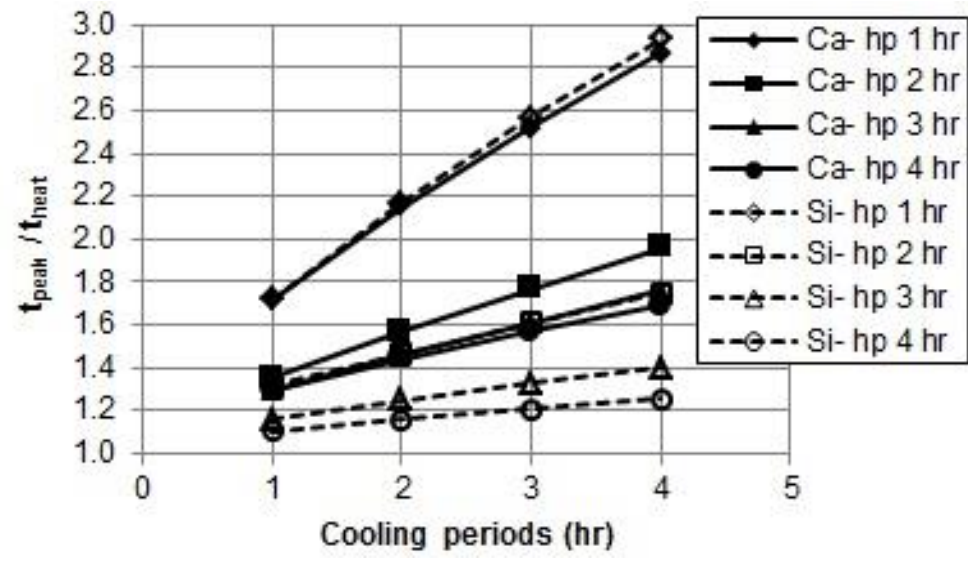

(b)

Fig. 12. Effects of heating and cooling periods on (a) $T_{\text {peak }} / T_{\text {heat }}$ ratio and (b) $t_{\text {peak }} / t_{\text {heat }}$ ratio at the steel reinforcement (concrete cover thickness of $50 \mathrm{~mm}$ ).

\subsection{Effects of Concrete Cover Thickness}

Figures 13 to 16 show the effects of concrete cover thickness, i.e., location of the critical steel reinforcement, on the $T_{\text {peak }} / T_{\text {heat }}$ and $t_{\text {peak }} / t_{\text {heat }}$ ratios for 1-h, 2-h, 3-h, and 4-h heating periods, respectively. It can be seen that both $\mathrm{T}_{\text {peak }} / \mathrm{T}_{\text {heat }}$ and $\mathrm{t}_{\text {peak }} / \mathrm{t}_{\text {heat }}$ ratios increase as the critical steel reinforcement locates more inside the section. As a longer cooling period allows more increase in steel temperature and delayed time, the most detrimental effect occurs in case of the longest $(4 \mathrm{~h})$ cooling and shortest $(1 \mathrm{~h})$ heating periods. For both carbonate and siliceous concrete beams, the increases in steel temperature after heating are found to be approximately 35, 50, and 75\% for concrete cover thicknesses of 30, 40, and $50 \mathrm{~mm}$, respectively. The effects of concrete cover thickness on both increases in steel temperature after heating and delayed time become less pronounced as heating period increases.

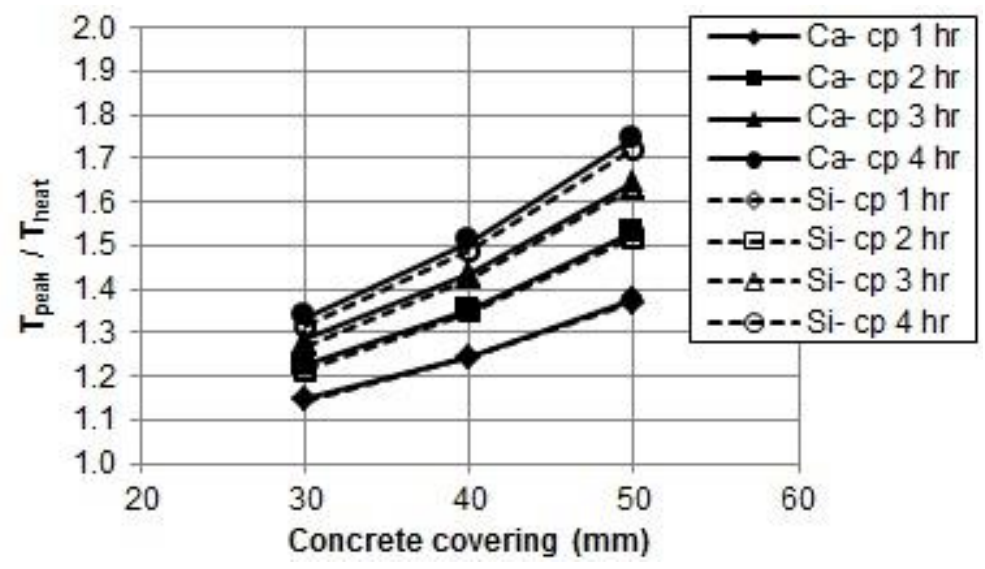

(a) 


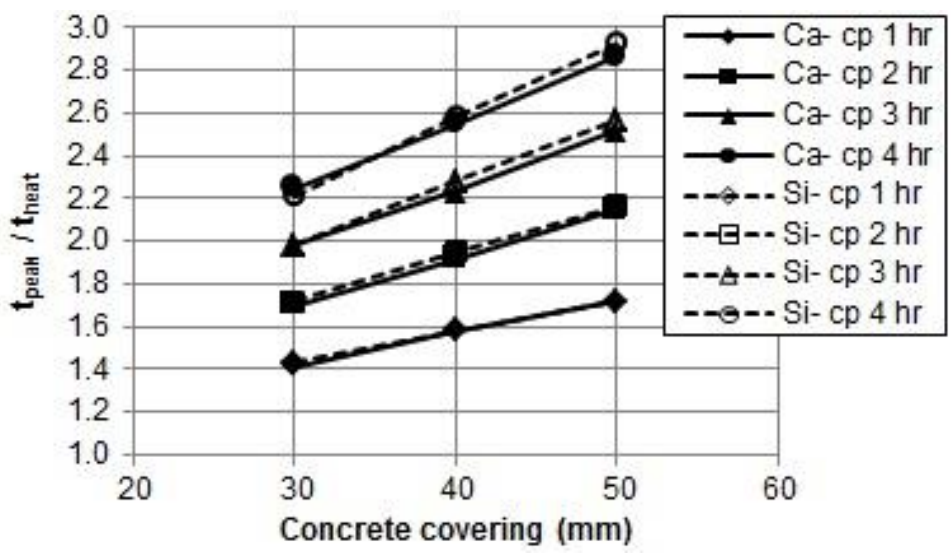

(b)

Fig. 13. Effects of concrete cover thickness on (a) $T_{\text {peak }} / T_{\text {heat }}$ ratio and (b) $t_{\text {peak }} / t_{\text {heat }}$ ratio at the steel reinforcement (1-h heating).

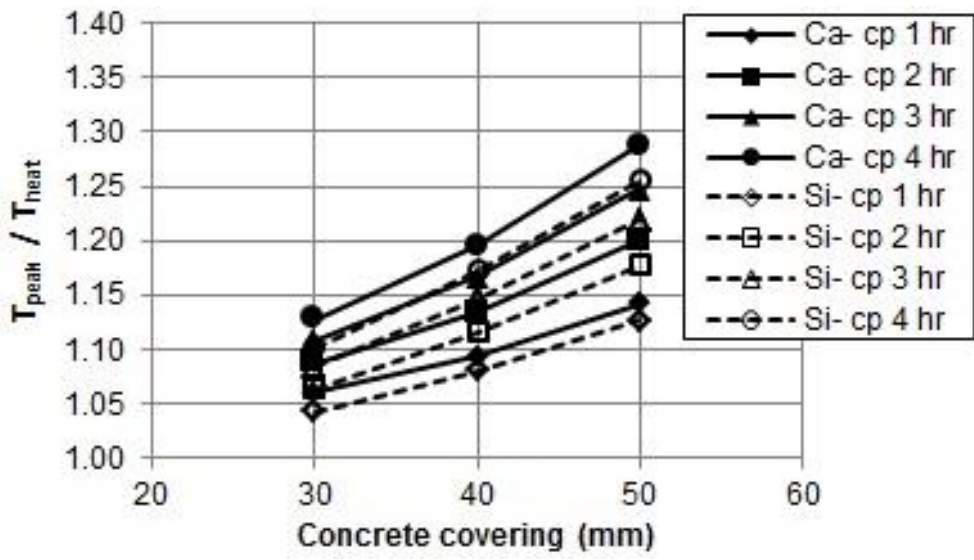

(a)

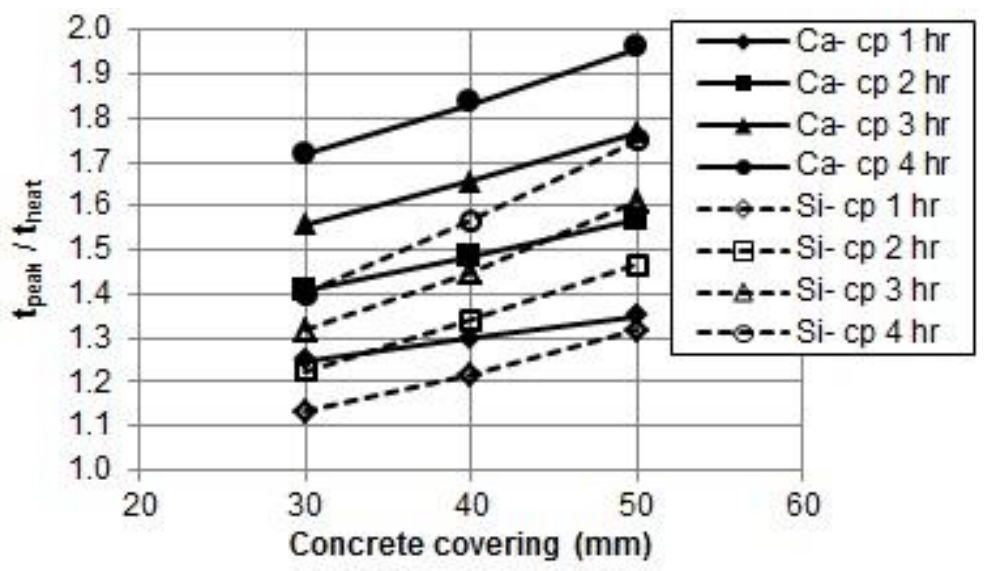

(b)

Fig. 14. Effects of concrete cover thickness on (a) $T_{\text {peak }} / T_{\text {heat }}$ ratio and (b) $t_{\text {peak }} / t_{\text {heat }}$ ratio at the steel reinforcement (2-h heating). 


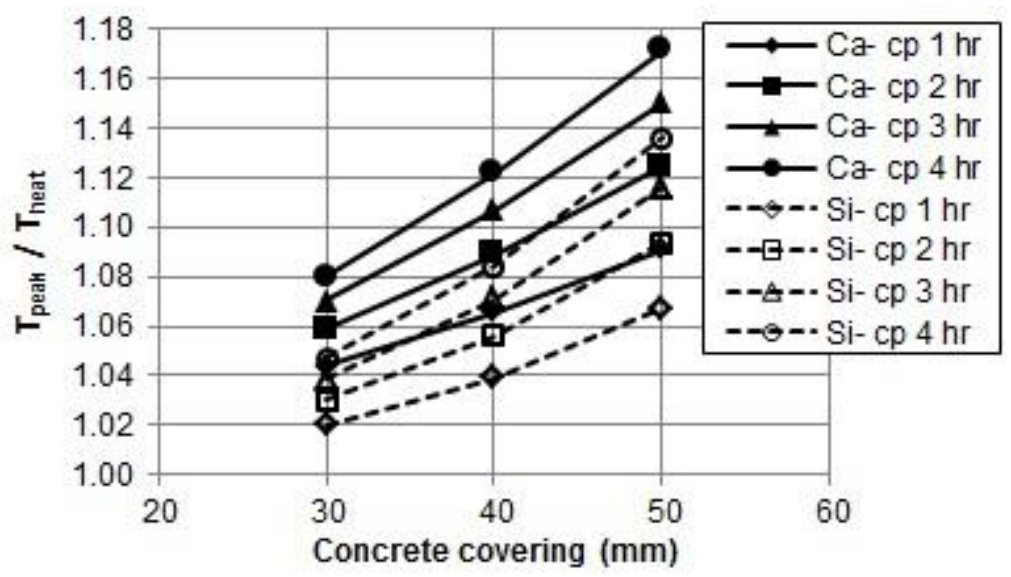

(a)

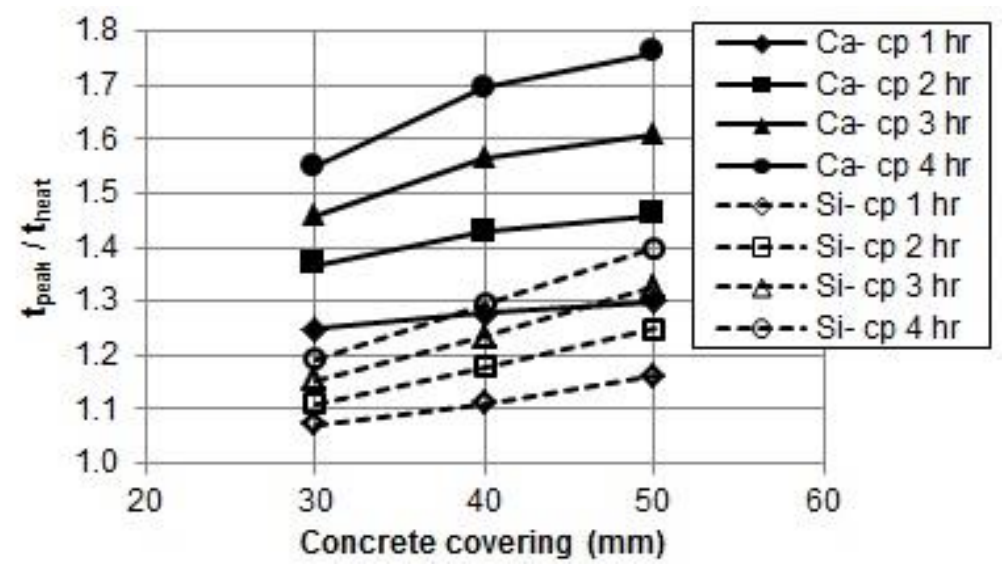

(b)

Fig. 15. Effects of concrete cover thickness on (a) $T_{\text {peak }} / T_{\text {heat }}$ ratio and (b) $t_{\text {peak }} / t_{\text {heat }}$ ratio at the steel reinforcement (3-h heating).

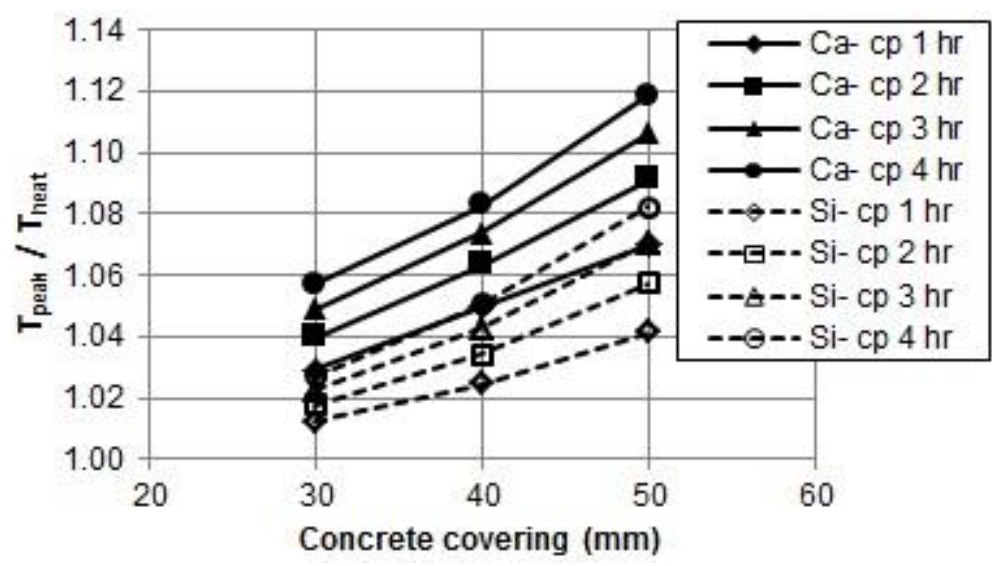

(a) 


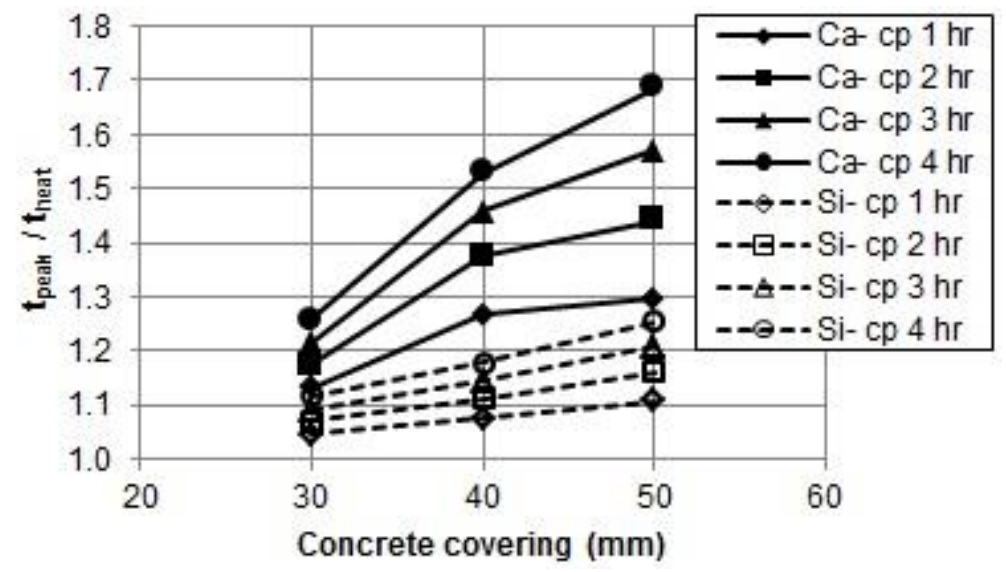

(b)

Fig. 16. Effects of concrete cover thickness on (a) $T_{\text {peak }} / T_{\text {heat }}$ ratio and (b) $t_{\text {peak }} / t_{\text {heat }}$ ratio at the steel reinforcement (4-h heating).

\section{Conclusions}

In this paper, a simplified 2D nonlinear transient thermal analysis of fire-exposed reinforced concrete beams based on the finite element method is described. The proposed analysis was used to investigate the effects of thermal loadings, concrete properties, and concrete cover thickness on the peak temperature distribution in the RC beam section with the emphasis on the temperature at the critical steel reinforcement in tension. From the numerical results, the main conclusions can be drawn as follows,

- When the rectangular RC beams are subjected to a three-sided fire exposure, the steel reinforcement located at the bottom corner is the most critical. The temperature inside the beam section continues to increase after heating, i.e., the peak temperatures are attained during the cooling period. The increases in steel temperature and delayed time are influenced by heating period, cooling period, location of steel reinforcement, and aggregate type.

- The increases in steel temperature and delayed time become more significant when the beam is subjected to a short heating and long cooling periods.

- A gradual cooling associated with a long cooling period causes more increase in steel temperature than a sudden cooling after heating. The most detrimental effect occurs in the case of longest (4-hr) cooling and shortest (1-hr) heating where the increases in steel temperature after heating in both carbonate and siliceous concrete beams are approximately 35, 50, and 75 percent for concrete cover thicknesses of 30, 40, and $50 \mathrm{~mm}$, respectively.

- The effect of cooling period on the increase in steel temperature becomes less pronounced as the heating period increases, which implies a high steel temperature caused by a long heating. For the heating period beyond $2 \mathrm{~h}$, the increases in steel temperature are less than 15, 20, and 30\% for concrete cover thicknesses of 30,40 , and $50 \mathrm{~mm}$, respectively.

- The effect of aggregate type (carbonate or siliceous) on the increase in steel temperature is minimal at a short heating period $(\leq 1 \mathrm{~h})$, but becomes significant at long heating periods. The carbonate concrete beams are more vulnerable to fire damage than siliceous ones when subjected to long heating and cooling periods.

- Both rises in steel temperature and delayed time are higher as the steel reinforcement locates more inside the section, i.e., thicker concrete covering. A longer cooling period allows more increase in steel temperature.

\section{Acknowledgements}

This research is supported by the 90th Anniversary of Chulalongkorn University Fund (Rachadapiseksompote Endowment Fund). The authors also acknowledge the Ratchadapiseksomphot Endowment under Outstanding Research Performance Program (Grant no. GF_58_07_21_01). 


\section{References}

[1] V. K. R. Kodur, M. B. Dwaikat, and R. S. Fike, "An approach for evaluating the residual strength of fire exposed to RC beams," Mag. Concrete Res., vol. 62, no. 7, pp. 479-488, 2010.

[2] M. Abramowicz and R. Kowalski, "Residual mechanical material properties for reassessment of reinforced concrete structures after fire," The 9th International Conference: Modern Building Materials, Structures and Techniques, Lithuania, May, 2007. Available: http://leidykla.vgtu.lt/conferences/MBM_2007/6pdf/Abramowicz.pdf [Accessed: 19 August 2016]

[3] M. B. Dwaikat and V. K. R. Kodur, "Response of restrained concrete beams under design fire exposure," J. Struct. Eng., vol. 135, no. 11, pp. 1408-1417, 2009.

[4] Y. Xu, B. Wu, M. Jiang, and X. Huang, "Experimental study on residual flexural behavior of reinforced concrete beams after fire exposure to fire," Adv. Mater. Res., vol. 457-458, pp. 183-187, 2012.

[5] U. Wickström, "A very simple method for estimating temperatures in fire exposed concrete structure," in New Technology to Reduce Fire Losses and Costs, S. J. Grayson and D. A. Smith, Eds. London, UK: Elsevier Applied Science, 1986, pp. 186-194.

[6] Y. Zandi, O. Burnaz, and A. Durmus, "Determining the temperature distributions of fire exposed reinforced concrete cross sections with different methods," Res. J. Env. Earth Sci., vol. 4, no. 8, pp. 782-788, 2012.

[7] D. D. Capua and A. R. Mari, "Nonlinear analysis of reinforced concrete cross-sections exposed to fire," Fire Safety J., vol. 42, pp. 139-149, 2007.

[8] V. K. R. Kodur and M. Dwaikat, "A numerical model for predicting the fire resistance of reinforced concrete beams," Cement Concrete Comp., vol. 30, pp. 431-443, 2008.

[9] V. K. R. Kodur, B. L. Yu, and M. M. S. Dwaikat, "A simplified approach for predict temperature in reinforced concrete members exposed to standard fire," Fire Safety J., vol. 56, pp. 39-51, 2013.

[10] W. Y. Gao, J. G. Dai, and J. G. Teng, "Simple method for predicting temperatures in reinforced concrete beams exposed to a standard fire," Adv. Struct. Eng., vol. 17, no. 4, pp. 573-589, 2014.

[11] J. H. Hsu and C. S. Lin, "Effect of fire on the residual mechanical properties and structural performance of reinforced concrete beams," J. Fire Prot. Eng., vol. 18, pp. 245-274, 2008.

[12] E. U. Chowdhury, L. A. Bisby, M. F. Green, and V. K. R. Kodur, "Residual behavior of fire-exposed reinforced concrete beams prestrengthened in flexure with fiber-reinforced polymer sheets," J. Compos. Constr., vol. 12, no. 1, 61-68, 2008.

[13] H. Lakhani, T. Singh, A. Sharma, G. R. Reddy, and R. K. Singh, "Prediction of post fire load deflection response of RC flexural members using simplistic numerical approach," Struct. Eng. Mech., vol. 50, no. 6, pp. 755-772, 2014.

[14] J. Ožbolt, J. Bošnjak, G. Periškića, and A. Sharma, "3D numerical analysis of reinforced concrete beams exposed to elevated temperature," Eng. Struct., vol. 58, pp. 166-174, 2014.

[15] ANSYS, ANSYS User's Manual, ANSYS, Inc., Canonsburg, Pennsylvania, 2014.

[16] ASCE, "Structural fire protection: manual of practice no. 78," Committee on Fire Protection, Structural Division, American Society of Civil Engineers, New York, 1992.

[17] V. K. R. Kodur, M. M. S. Dwaikat, and M. B. Dwaikat, "High-temperature of concrete for fire resistance modeling of structures," ACI Mater. J., vol. 105, no. 5, pp. 517-527, 2008.

[18] M. I. Khan, "Factors affecting the thermal properties of concrete and applicability of its prediction models," Build. Environ., vol. 37, pp. 607-6 14, 2002.

[19] A. L. Marshall, "The thermal properties of concrete," Build. Sci., vol. 7, pp. 167-174, 1972.

[20] A. H. Buchanan, Fire Engineering Design Guide. New Zealand: Centre for Advanced Engineering, University of Canterbury, 2001.

[21] V. K. R. Kodur, "Properties of concrete at elevated temperatures," ISRN Civil Engineering, vol. 2014, Article ID 468510, 2014. [Online]. Available: http://dx.doi.org/10.1155/2014/468510 [Accessed: 19 August 2016]

[22] ASTM E119-08, Standard Test Methods for Fire Test of Building Construction and Materials, American Society for Testing and Material, West Conshohocken, Pennsylvania, 2008.

[23] F. Kreith, R. M. Manglik, and M. S. Bohn, Principles of Heat Transfer. Colorado: Cengage Learning, 2011.

[24] B. Jacob, A. Balaji, and E. John, "Behaviour of concrete structures under fire - A comparative study between IS 456: 2000 and finite element software ANSYS," AJER, vol. 3, pp. 62-66, 2013. 
[25] T. T. Lie and R. J. Irwin, "Method to calculate the fire resistance of reinforced concrete columns with rectangular cross section," ACI Struct. J., vol. 90, no. 1, pp. 52-60, 1993.

[26] C. A. Wade, "Summary report on a finite element program for modeling the thermal response of building components exposed to fire," Building Research Association of New Zealand., BRANZ Study Report No. 51, Judgeford, New Zealand, 1993.

[27] W. Y. Gao, J. G. Dai, J. G. Teng, and G. M. Chen, "Finite element modeling of reinforced concrete beams exposed to fire," Eng. Struct., vol. 52, pp. 488-501, 2013.

[28] R. L. Emberley, "A study into the behavior of reinforced-concrete columns under fire exposures using spreadsheet-based numerical model," M.S. Thesis, Worcester Polytechnic Institute, Worcester, 2013.

[29] S. Tiantongnukul, "Flexural analysis of fire-exposed reinforce concrete beams strengthened with fiberreinforced polymer plates," (in Thai), M.Eng. Thesis, Dept. of Civil Engineering, Chulalongkorn Univ., Bangkok, Thailand, 2014. 